\title{
História da literatura: estética e projeto nacionalizante
}

\author{
Wandersson Hidayck Silva* \\ Universidade Federal de Pernambuco \\ Recife, Brasil \\ Recebido em: 24/06/2019 \\ Aceito em: 01/o8/2019
}

Resumo: Considerações a respeito do modelo historicista de visão positivista e diacrônica empregado na história da literatura tradicional, resultante de projetos nacionalistas. Questionam-se as limitações desse enfoque teóricometodológico e se propõe uma história literária que considere o elemento estético em sua abordagem.

Palavras-chave: Literatura e História. Historiografia Literária. Literatura e Crítica.

Abstract: Considerations regarding the historicist model of positivist and diachronic vision employed in the history of traditional literature, resulting from nationalist projects. We question the limitations of this theoreticalmethodological approach and propose a literary history that considers the aesthetic element in its approach.

Keywords: Literature and History. Literary Historiography. Literature and Criticism.

Resumen: Consideraciones acerca del modelo historicista de visión positivista y diacrónica empleado en la historia de la literatura tradicional, resultante de proyectos nacionalistas. Se cuestionan las limitaciones de ese enfoque teórico-metodológico y se propone una historia literaria que considere el elemento estético en su abordaje.

Palabras clave: Literatura e Historia. HistoriografíaLiteraria. Literatura y Crítica. 


\section{Introdução}

A história da literatura tradicional tem suas bases teóricas e metodológicas no modelo historicista diacrônico e positivista, que encara a sucessão dos fatos no tempo como um encadeamento homogêneo e direcionado a um progresso futuro. Nesse modelo, as obras literárias são agrupadas em escolas ou movimentos de categorias fixas e se relacionam com a sociedade como um reflexo desta. Além disso, os aspectos intrínsecos ao texto, sua qualidade formal, estética, são subestimados ou desprezados em face da narrativa da contextualização histórica das obras, que propõe a ideia de que a literatura existe em conformidade com as marcas de seu tempo. Isso se deu, nas origens dessa disciplina, devido aos projetos nacionalizantes aos quais ela pertenceu; a literatura deveria ajudar a compor a história de uma nação, favorecendo o ideal de uma consciência patriótica.

Tendo passado o tempo da inclusão da literatura em um projeto nacional, as marcas da adoção desse modelo historicista sobrevivem nos ensinos básico e acadêmico dessa disciplina no Brasil, em geral, tanto nas propostas teóricas quanto na estruturação das grades curriculares. $O$ ranço historicista também reverbera em estudos que apresentam as condições históricas como elementos condicionantes e explicativos das obras literárias.

Nesse contexto, teóricos e críticos da literatura questionam os pontos de vista e métodos empregados na história literária que se escreve, bem como nos equívocos e limitações da história já escrita, aliada à formação de uma tradição cultural para a qual também se lança um novo olhar, contestador. Essas reflexões levam em conta o papel do leitor e seu lugar na história enquanto receptorrefazedor do texto literário e propõem uma relação dialética entre as obras no passar do tempo, que não é linear nem se encaminha para um futuro redentor. Estabelecem-se, assim, novas perspectivas de historiografia e análise literária, que atentam para o conhecimento recente sobre literatura e discurso histórico. 
Neste artigo, comenta-se, à luz de autores que refletiram consistentemente sobre esse tema, ineficiências da abordagem historicista e propostas de um viés sincrônico atento ao valor estético do texto literário.

\section{A história da literatura como programa institucional}

Segundo Antonio Candido, em seu livro Formação da literatura brasileira, foi entre meados do século XVIII (1750) e a metade do século XIX que se configurou, no Brasil, o sistema literário - termo atribuído pelo crítico à articulação de elementos dinâmicos que definem a existência de uma literatura atuante em determinado contexto histórico-geográfico, a saber três elementos: os autores, as obras e os públicos - , consolidando-se da segunda metade do século XIX à contemporaneidade. Para que esse sistema se formasse, em nosso país, o projeto de uma literatura independente, do modelo europeu colonizador, foi fundamental, reflexo do projeto de independência política, oficialmente consumado em 1822. Antes dessa tomada de posição dos autores, conforme Candido, os textos literários escritos no território nacional formavam uma produção dispersa, sem caráter próprio que a identificasse, sem objetivos ideológicos claros, linguagem particular nem unidade. Assim, não formavam um sistema, eram simplesmente manifestações literárias.

Foi com o neoclassicismo e, especialmente, o Romantismo, na sua busca de uma literatura genuinamente nacional, que essa realidade se modificou. Os escritores, em sua maioria, passaram a buscar no patriotismo (com alusão a história, tradições, religião, natureza) e no indianismo elementos que, por sua pretensa singularidade, oferecessem à literatura feita no Brasil a tão sonhada independência. Aliada às mudanças temáticas, estava a experimentação formal em novos gêneros literários, que atendessem às novas ideias, entre as quais republicanas e abolicionistas. E, ao passo que os aspectos externos davam a cor local às obras, também se prezava pela individuação, unindo, desse modo, o nacional ao pessoal. 
Para Antonio Candido, trata-se de um grande momento da história da literatura brasileira, pelo empenho do seu projeto coeso, tanto entre os artistas como entre os críticos. Ele afirma que foi a partir daí que se teve início uma tradição literária no Brasil. O crítico, acusado de desprezar a produção artística anterior ao Arcadismo brasileiro em sua explanação do conceito de sistema literário, defende-se, no prefácio à segunda edição do livro, reafirmando que somente no século XVIII a literatura do país adquiriu uma "densidade apreciável”, mas que houve, em "sentido amplo", literatura no Brasil desde o século XVI.

A ideia de literatura como expressão do projeto de Estado-Nação também estruturou modelos de ensino de literatura empregados até hoje em escolas e cursos universitários de Letras. É dado um enfoque cronológico e historicista tanto nos livros didáticos, que encaixam as obras literárias nas chamadas escolas, períodos estanques de criação, como nas grades curriculares do ensino superior.

Roberto Acízelo de Souza aponta três traços fundamentais na disciplina história da literatura, que teve seu auge no século XIX: seu caráter de gênero discursivo, vinculado à narrativa épica, com sua concepção linear do tempo e enfoque patriótico; seu caráter científico, no emprego de métodos e técnicas; e seu caráter institucional, formalizando, nos sistemas de ensino, um cânone literário nacional. Em seu livro História da literatura(2014), o professor ainda discorre sobre a razão de essa disciplina ter se tornado constitutiva dos planos de ensino escolares:

Senhora de um objeto assim tão estratégico para a sondagem e a
identificação do "caráter nacional", a história da literatura por esse
motivo viria a ocupar posição de relevo entre os mecanismos
institucionais de salvaguarda dos valores das nações; por isso, entre as
subdivisões tradicionalmente reconhecidas da história nacional -
história eclesiástica, militar, administrativa, diplomática, etc. -, foi a
única que se instalou, ao lado de uma história que se poderia qualificar
como geral (na verdade, de dominância política), nos currículos
escolares, integrando assim os sistemas de educação cívica implantados
nos vários Estados nacionais modernos. (SOUZA, 2014, p. 6o)

Roberto Acízelo aponta que, a partir do final do século XIX, a disciplina história da literatura começa a perder seu lugar central nos estudos literários, com o questionamento do paradigma historicista e sua visão diacrônica, 
culminando com a elaboração da teoria da literatura, a qual se ocuparia em corrigir a denunciada lacuna da história da literatura: sua primazia pelos fatores extrínsecos ao texto literário. Conforme o autor, em três momentos do século XX, observaram-se movimentos de revitalização histórica nos estudos literários: o formalismo, que se voltou contra a história tradicional com seu conceito de evolução da dinâmica literária; a estética da recepção, que trouxe o público leitor como elemento-chave em suas análises; e o novo historicismo, preocupado em discutir as fronteiras entre literatura e história, observando a textualidade em ambas.

Com o enfraquecimento das ideologias nacionalistas, a institucionalização da história da literatura passou a ser acusada de, em sua adequação ao nacionalismo burguês, formalizar um cânone literário atrelado aos ideais daquele projeto, deixando de lado obras que não contribuíssem para a homogeneização pretendida. A partir de meados do século XX, com a intensificação dos estudos da linguagem e suas implicações no novo modo de se estudar a literatura (imanentista), tal cânone é continuamente revisto e questionado, bem como os possíveis critérios de seu fazimento. Corroboram com essa iniciativa, os estudos culturais, que reivindicam um olhar mais atento às produções de grupos sociais historicamente marginalizados nos contextos de produção artística.

Roberto Acízelo de Souza, no tocante a esse tema, faz algumas provocações:

- o comportamento arisco a todas as formas de poder (entre elas, segundo os pesquisadores dos estudos culturais, a história da literatura e a própria literatura) e o consequente relativismo cultural não "acaba conduzindo à descrença em qualquer projeto coletivo, e, portanto, à exaltação do individualismo?" (SOUZA, 2014, p.69)

- já que o desconstrutivismo típico dessa linha de pesquisa - que engloba todas as manifestações culturais no conceito de discurso, retirando-lhes valorações - é realizado por professores formados na tradição historicista dos centros universitários, na qual tiveram acesso aos grandes esquemas literários, não se pode dizer que sem esse conhecimento tradicional tão execrado não haveria como questionar o modelo historicista? 
- a cultuada transdisciplinaridade, e seu desprezo pelo rigor técnico da teoria literária, analisando com o mesmo instrumental a literatura e diversas outras produções culturais e entrecruzando inúmeros campos de conceituação para analisar questões não literárias, não seria "um recuo ao historicismo extrínseco e sua integral confiança nas explicações ecléticas?” (SOUZA, 2014, p. 71)

Ao final de seu estudo, Roberto Acízelo de Souza fala sobre a "Pertinência da história literária" (SOUZA, 2014, p. 97). O autor propõe que os estudos culturais, para ele grandes inimigos da história da literatura, sejam deslocados para os cursos de comunicação ou Ciências Sociais ou ainda diluídos na teoria da literatura, "como de resto se procede quanto a outras disciplinas" (SOUZA, 2014, p. 106), e sugere que, nos cursos universitários de Letras, a ordem das disciplinas seja invertida na grade curricular: antes a história da literatura, depois a teoria. A problematização do autor em relação à permanência da história da literatura na academia não vai muito além dessa proposta e não indica, por exemplo, possíveis modos de reverter limitações conceituais da disciplina nem mudanças em sua metodologia. $\mathrm{O}$ autor não reflete, também, sobre um diálogo mais estreito entre as duas correntes de pesquisa. Pelo contrário, indica que a teoria da literatura deveria se manter à parte da história, recorrendo a esta apenas para obter informações "primárias".

No entanto, mais interessante seria que se revisse justamente essa dicotomia e que tanto a história como a teoria ocupassem o centro dos estudos literários. Como o professor reconhece, a teoria não pode desprezar a história porque necessita dela para situar obras, autores e movimentos artísticos no tempo e no espaço, bem como para entender como a realidade exterior dialoga com o texto literário. Mas precisamos acrescentar que a história também não deveria desprezar a teoria, antes se valer de seu teor reflexivo para questionar a essência e construção de seu discurso.

Inverter a grade curricular dos cursos de Letras seria menos proveitoso que alterá-la em suas bases, que refletem uma visão historicista ainda apegada ao modelo diacrônico, evolutivo e progressista. Estudar a literatura por períodos 
estabelecidos pela história tradicional em muito se distancia do dinamismo e da fragmentação contínuos pelos quais passa a sociedade e suas manifestações culturais. O modelo historicista vai na contramão da própria literatura, que constantemente questiona o presente e o passado e se refaz de influências das mais diversas épocas.

\section{A história e o valor estético da literatura}

No prefácio à segunda edição do Formação da literatura brasileira (200o), Antonio Candido comenta o método empregado em seu estudo crítico-histórico:

[...] um método que seja histórico e estético ao mesmo tempo, mostrando, por exemplo, como certos elementos da formação nacional (dado histórico-social) levam o escritor a escolher e tratar de maneira determinada alguns temas literários (dado estético). (CANDIDO, 200o, p.16)

Ainda nesse prefácio, comentando a sua tese Introdução ao método crítico de Sílvio Romero, Candido reconhece a importância de se levar em conta, como aspecto fundamental, o caráter estético da obra literária, buscando identificar os modos como esse aspecto se relaciona com fatores externos à obra, demonstrando uma postura crítico-teórica que ele levaria adiante em estudos futuros, a de aliar fatores externos e internos na literatura:

[...] procurei, ainda, mostrar até que ponto a consideração dos fatores externos (legítima e, conforme o caso, indispensável) só vale quando submetida ao princípio básico de que a obra é uma entidade autônoma no que tem de especificamente seu. Esta precedência do estético, mesmo em estudos literários de orientação ou natureza histórica, leva a jamais considerar a obra como produto; mas permite analisar a sua função nos processos culturais. (CANDIDO, 2000, p. 16)

Seguindo a linha de pensamento de Antonio Candido, uma história da literatura deveria, antes de tudo, construir-se sob a defesa do elemento estético como essencial na análise dos processos que envolvem a produção, circulação e 
recepção das obras. Desse modo, uma obra não estaria automaticamente atrelada a um movimento ou escola literária tão somente porque seu autor viveu em determinados lugar ou época. Muito menos a história da literatura se resumiria a identificar a que segmentos sociais pertence determinado autor, seu gênero, orientação sexual, cor, classe econômica, etc. Antes, as características verbais (formais) significativas de uma obra a colocariam em diálogo com este ou aquele grupo artístico, de qualquer tempo, ou ainda com nenhum, tratando-se, nesse caso, de uma obra extremamente peculiar sem conexões possíveis no horizonte vigente.

Uma abordagem formal da história da literatura é a defesa de Michael Riffaterre, para quem a simples descrição de fatos exteriores ao texto literário pouco contribuem para a história da literatura, a qual deve levar em conta os elementos formais estruturais das obras, pois a história da literatura "só é válida se ela se torna história das palavras" (RIFFATERRE, 1989, p.98).

Riffaterre (1989) discorre que os componentes textuais da literatura são imprescindíveis na construção de uma história literária, já que os historiadores dessa arte recorrem constantemente aos elementos lexicais e semânticos das obras analisadas para, assim, filiá-las a determinado gênero e identificar as influências de outros textos na confecção de tais obras.

Segundo ele, com frequência se observam na literatura os chamados sistemas descritivos: conjuntos de expressões verbais de significação aproximada que se referem a estereótipos e clichês pertencentes ao espírito de uma época. Porém, a identificação de tais sistemas em textos diferentes não é suficiente para estabelecer uma relação de influência entre eles. Assim como as coincidências cronológicas - como autores diferentes descreverem o mesmo tema em épocas próximas - não são suficientes para aproximar esses autores nem associar a obra deles a determinado gênero literário. Já que:

Apenas o estudo da estrutura do poema pode levar a uma segmentação pertinente de seus componentes, a uma segmentação que recupere e defina as formas que lhe são próprias. Toda segmentação preconcebida (com base, por exemplo, em uma comparação palavra por palavra, sem considerar a sintaxe) está condenada ao fracasso. (RIFFATERRE, 1989, p.84, grifo meu) 
O autor salienta que o estudo das leituras sucessivas, ou da sobrevida, de uma obra deve se realizar observando a tensão entre dois códigos: o do texto, empregado pelo autor e imutável (no qual se conservam os sistemas descritivos), e o do leitor, sempre mutável. Essa tensão vai indicar, por exemplo, as estranhezas que um texto causa em determinado contexto, mas não em outro, como é o caso dos neologismos, que, se forem assimilados na linguagem corrente, deixam de oferecer o impacto das primeiras leituras. Processo parecido pode ocorrer com arcaísmos e alusões literárias: por vezes se tornam datados. Por outro lado, mesmo textos que contenham traços linguísticos não mais frequentemente empregados podem revelar uma estrutura cujo funcionamento permanece ativo, possibilitando, dessa forma, a compreensão do texto pelo leitor.

Riffaterre (1989) defende, então, que a história da literatura deveria se ocupar não apenas com as origens dos sistemas descritivos, mas com suas atualizações, inclusive para reconstruir os significados originais de um texto, o que só é possível com um enfoque formal da materialidade linguística.

Esse modelo de história da literatura, como se nota, não abre mão da perspectiva diacrônica, mas submete-a a um corte sincrônico, promovendo uma relação de complementaridade entre as duas formas de descrição histórica. No estudo A arte no horizonte do provável, Haroldo de Campos explica que a poética diacrônica exerce a função de contextualizar a obra literária no tempo, mas não questiona a valoração que a tradição atribuiu com o passar dos anos. Já a poética sincrônica lança um olhar ativo e dinâmico sobre a produção literária, tornando possível, inclusive, retificar o senso comum estabelecido pelo modelo diacrônico. Enfatizando essa dialética, o crítico discorre:

Para mim, a poética sincrônica é sempre uma poética situada na acepção sartriana do termo. Neste sentido ela não opera no vazio (“a literatura não existe no vácuo”, já proclamava Ezra Pound), mas está inserida na história; só pode assumi-la um homem datado e inscrito num dado tempo histórico, o presente. (CAMPOS, 1975, p. 216)

Esse situamento do leitor na história é o tema de que se ocupa João Alexandre Barbosa no seu artigo As ilusões da modernidade. Na poesia moderna, conforme o autor, ocorre não mais um processo de decifração dos códigos 
significantes do poema, mas uma recifração, na qual o leitor é responsável por delimitar, junto com o poeta, no ato da leitura, as possíveis significações do texto. É um jogo reflexivo em que a escrita do poeta já está imbuída da consciência de leitura, ou seja, a "implicação do leitor no poeta" (BARBOSA, 1986, p.14). E tal consciência, crítica em sua essência, permite que se recupere a qualidade histórica do texto poético, como diz o autor:

[...] o poeta moderno é aquele que sabe o que há de instável na condição de encantamento de seu texto, sempre dependente de sua condição de enigma. Consciência e história são vinculadas pelo mesmo processo de intertextualidade: o novo enigma é a resolução transitória de numerosos enigmas anteriores. (BARBOSA, 1986, p. 15)

O processo de intertextualidade é, então, central no poema moderno e ele nasce do questionamento, por parte do poeta, da própria linguagem da poesia. $\mathrm{O}$ poeta é responsável, no ato de escrever que já implica também um ato de leitura, por "criar o espaço para a atualização da cultura" em seu texto (BARBOSA, 1986, p. 16). Na linguagem do poema, há não somente interseções da tradição cultural, como da linguagem das circunstâncias, histórica e a social, estabelecendo-se, assim, dois tempos que se vinculam à relação entre o poeta e a sociedade.

João Alexandre Barbosa chama a atenção para a relação ambígua que se instaura na modernidade, com as novas perspectivas de escrita e leitura, entre leitor e texto (autor): a linguagem empregada no poema, ausente de um sentido único que conforte quem lê à sua expectativa de leitura, a qual pode aparentar um desprezo pelo leitor, na verdade torna o público indispensável na construção do poema, que continua a se realizar em cada nova leitura. Como aparentes obstáculos à fruição do poema moderno pelo leitor, estão: o obscurecimento das imagens, tornando complexas suas referenciações; as tensões metafóricas, que suspendem a distância entre palavra e sujeito da linguagem; a retenção da subjetividade, adensada na objetividade; os procedimentos alegóricos, que questionam o vínculo entre verbo e realidade. Desse modo se acentua a historicidade do texto literário. Segundo o crítico: 
O desprezo aparente, portanto, não é senão a afirmação de uma dependência ainda maior. Enquanto encantamento, o poema é pensado e realizado para o leitor, enquanto enigma, todavia, e é o caso do poema moderno, entre leitor e poeta estabelece-se a parceria difícil de quem joga o mesmo jogo. (BARBOSA, 1986, p. 22)

O autor também afirma que a tradução é responsável por recuperar a historicidade do poema, já que ela torna possível uma nova leitura das formas poéticas com a ressignificação da linguagem.

Há em comum, no pensamento de Michael Riffaterre, Haroldo de Campos e João Alexandre Barbosa, a respeito de uma eficiente história da literatura, dois pontos: a centralidade do valor estético da obra literária (também citada por Antonio Candido) e a presença da relação do texto com o leitor. O primeiro ponto permite observar tanto os elementos que não se modificam no texto com o passar do tempo como os que são atualizados em novos contextos de recepção. E o segundo, a relação texto $x$ leitor, oferece os indícios necessários para se elucidarem essas atualizações.

\section{Conclusão}

A história da literatura serve a propósitos ideológicos, e, quando tais propósitos se tornam institucionais, modificá-los se torna uma tarefa ainda mais complexa, dada a aparência de perenidade e imutabilidade que seu caráter oficial oferece. No entanto, no caso dessa disciplina, existem, como vimos, questionamentos consistentes em relação aos enfoques teóricos e metodologias, os quais comprometem toda a formulação dos estudos literários nas escolas e universidades.

Baseada no modelo historicista tradicional, de sentido unívoco, oriundo de um projeto nacionalizante e, portanto, progressista, a história literária que ainda hoje baliza os modelos de ensino de literatura representa um entrave ao avanço de um estudo que reflita as interseções entre história, sociedade e cultura levando em conta as especificidades de cada manifestação cultural, nesse caso do texto 
literário, e as influências mútuas entre elas. A literatura, no modelo questionado, é produto da história, sendo por esta delimitada. No entanto, as inúmeras reflexões já realizadas sobre o diálogo transversal entre texto e sociedade comprovam a ineficácia da aplicação da visão exclusivamente diacrônica no estudo da literatura. Essas reflexões precisam ser mais debatidas no espaço acadêmico, entre alunos e professores para que, daí, surjam novas propostas de crítica e ensino da literatura que acompanhem o desenvolvimento das discussões dos modelos teóricos empregados na historiografia.

Sendo assim, a história da literatura deveria estar em consonância com a valorização do elemento estético do texto literário, enfatizado com a teoria da literatura. Pois, a simples narração dos agentes externos que rodeiam as obras em seus momentos de produção e a periodização de escolas literárias não acrescentam ao entendimento dos modos como as obras literárias modificam a tradição a que pertencem nem como se ligam a essa tradição de forma dialógica, e não verticalizada. E, acima de tudo, não fazem com que a história da literatura cumpra um objetivo importante: formar leitores capazes de entender o sofisticado sistema de influências socioculturais envolvidas na produção literária e, assim, quem sabe, enxergar a literatura como uma fonte de engrandecimento pessoal e, por consequência, social.

\section{Referências}

BARBOSA, João Alexandre. As ilusões da modernidade: notas sobre a historicidade da lírica moderna. São Paulo: Perspectiva, 1986.

CAMPOS, Haroldo de. A arte no horizonte do provável. São Paulo: Perspectiva, 1975 .

CANDIDO, Antonio. Formação da literatura brasileira: momentos decisivos. 6 ed. Belo Horizonte: Editora Itatiaia, 2000.

REIS, José Carlos. História e teoria: historicismo, modernidade, temporalidade e verdade. Rio de Janeiro: Editora FGV, 2006. 
RIFFATERRE, Michael. Para uma abordagem formal da história da literatura. In: A produção do texto. São Paulo: Martins Fontes, 1989.

SOUZA, Roberto Acízelo de. História da literatura: trajetória, fundamentos, problemas. São Paulo: É Realizações, 2014.

* Doutorando em Teoria Literária pela UFPE 